\title{
Employing Police Training as a Tool of Preventive Intervention of Police Complex Trauma: A Brief Report from a Module Presented at the 2011 European Police College Train the Trainers Seminar
}

\section{Konstantinos Papazoglou ${ }^{1 *}$ and Christiane Manzella ${ }^{2}$}

${ }^{1}$ University of Toronto, Canada

${ }^{2}$ Applied Psychology, The Steinhardt School of Culture, Education, and Human Development, New York University, USA

\begin{abstract}
Currently, the focus and information about training police officers relates primarily to physical and mental fitness and ways to help others. There are very few resources and almost no information available to guide police officers about ways to handle loss and trauma. Officers respond to critical incidents that have the potential to be traumatic and that can precipitate a traumatic response that, in turn, may negatively affect their physical and mental health. The unique nature of a career in law enforcement is that trauma as inevitable and an expected part of the job and that unresolved effects of trauma have the potential to accumulate over a whole career. Police trainers/educators are in a unique position to address this because all police officers are often first-line responders and therefore, first line helpers. The authors provided a module related to training about trauma to European police educators participating in the 2011 "Train the Trainers" 2nd step seminar held in the Police University in Muenster, Germany. They introduced three interventions (education, journal writing, and a mindfulness/awareness exercise) to discern what was effective and possibly could be implemented into police training. It was clear that police trainers made the distinction that they are not therapists, but that they can be a supportive blue brother or sister to their trainees. The principal aim was to create bridges between law enforcement and mental health professionals so that the services developed and offered by mental health professionals could be useful and "palatable" to police officers.
\end{abstract}

Keywords: Police training; Complex trauma; European police

\section{Introduction}

Welten [1] gave a speech to the European police research and science conference and used the title "A brave police force deserves courageous scientists." His speech highlighted the need for trainers and educators in police forces to widen their perspectives and increase their collaboration with scientists to benefit from leading edge scientific data and findings. In this study, the authors offered a broadened perspective and alternative role for police educators designed to help them think and act as first line helpers for their trainees. As part of the overall training with Senior Police Educators from European countries participating in the Step 1 and Step 2 "Train the Trainers" seminar of the European Police College held in the Police University in Muenster, Germany, the authors provided a module during Step 2 related to training about trauma. They introduced three interventions (education, journal writing, and a mindfulness/awareness exercise) and also carried out a qualitative study in conjunction with the training to discern what was effective in handling trauma and that could potentially be implemented into police training.

\section{Broad Purpose and Rationale}

Police officers often act as social scientists through social action and community policing [2]. Taking this perspective, the authors describe a module to train senior police trainers to act and behave as social scientists, or more specifically, as first line helpers, including addressing mental health related to trauma. The authors' intention was to provide tools for senior police trainers to help their trainees become more aware of the nature and impact of exposure to critical incidents and, also more able to teach practical and doable ways for trainees to more effectively deal with physical and psychological adversities while on duty. In particular, the scope of the development and application of this module was to:
- identify ways senior police trainers/educators define and train about trauma

- provide tools for senior police trainers/educators to use as they train cadets and advanced police officers

- identify ways to incorporate healthier ways of processing trauma into police training

- identify and understand themes important to the senior police trainers/educators in this training

- identify and understand senior police trainers/educators responses to the training related to trauma

Trauma is defined in the DSM-IV-TR as exposure to a traumatic event that compromises the physical integrity or life of an individual and produces intense fear [3]. Currently, the focus and information about training police officers focuses mostly on physical fitness. Because police officers are often in the front line in providing help to victims/survivors of violence and trauma, the focus in training needs to expand to include ways to support and maintain officers' mental fitness as well as physical fitness while continuing the training focus

*Corresponding author: Konstantinos Papazoglou, University of Toronto, Canada, E-mail: kons.papazoglou@mail.utoronto.ca

Received November 23, 2012; Accepted December 29, 2012; Published December 31, 2012

Citation: Papazoglou K, Manzella C (2013) Employing Police Training as a Tool of Preventive Intervention of Police Complex Trauma: A Brief Report from a Module Presented at the 2011 European Police College Train the Trainers Seminar. J Forensic Res S11: 004. doi:10.4172/2157-7145.S11-004

Copyright: ( $\subset 2013$ Papazoglou K, et al. This is an open-access article distributed under the terms of the Creative Commons Attribution License, which permits unrestricted use, distribution, and reproduction in any medium, provided the original author and source are credited. 
related to effective and safe ways to help others. This need comes from the fact that police officers are the ones who are exposed to critical incidents and they are the first line professionals who often are called on to resolve a potentially life-threatening or traumatic situation. For instance, police officers responding to a domestic violence situation might find they need to rescue an abused child and call governmental agencies or a non-government agency expert to take care of that child. Handling violence and witnessing the horrific effects of child abuse can be very traumatic. It is vital that police officers are able to physically resolve the critical situation (the domestic violence incident and the child abuse) while also being able to efficiently function because they are able to process their emotional responses. Thereby, authors believe that police training can be employed as a vehicle to help active police trainees and the next generations of police officers, police cadets, become more aware of these issues. This could help them be more able to help themselves and at the same time have more capacity to help community members. The importance of the topic of this paper is derived from the fact that there have been only a few studies and books or training materials about police and trauma and only a few resources or information to guide police officers about ways to handle loss and trauma. Indeed, Neylan et al. [4] points out that although police officers are at a great risk of experiencing trauma, they are understudied in relation to other populations such as combat veterans.

\section{Police Culture and its Interface with Trauma}

The law enforcement field is characterized by a unique form of subculture, the so-called "police culture" [5], which is identified, on the one hand, by internal solidarity, brotherhood, and support and, on the other hand, by isolation from society. In the police culture, open expression of fear or emotions in response to highly charged events, including life-threatening and traumatic events on the job or loss of colleagues - often through completed suicide - is usually seen as being unacceptable [6]. This means that police officers often live a life of quiet desperation. Carlier et al. [7] contend that symptomatology of traumatized police officers was further predicted by their difficulty in expressing their emotions. Emotional expression is often considered weakness in the police culture and this view is a real obstacle and challenge in self-help efforts for police officers to resolve their trauma and for mental health professionals trying to help traumatized police officers. The need for emotional and cognitive flexibility that allows officers to function at a high level and to process responses to trauma is clear because police officers carry out wildly differing roles from moment to moment. That is, one moment a cop is arresting an offender: Stop! Freeze! High alert! The very next moment that same cop is comforting a mortally wounded person. Police officers often go from being a deliverer of social services to handling life-threatening and potentially horrific emergency in seconds.

The unique nature of a career in law enforcement is that police work inevitably involves trauma. Rudofossi [8] found that police officers encounter a range from 10 to 900 plus events that could potentially be classified as traumatic over their career. Moreover, Darensburg et al. [9] found that officers aged 50 years or older had 40\% higher PTSD prevalence ratio than officers aged 40 years or younger. Trauma is an expected part of the job for police officers and the effects of trauma have the potential to accumulate over a whole career that ranges from 20 to 30 years. In addition, these traumatic events "...are not ordinary events, regardless of how many times they are experienced" [6]. Trauma exposure in police work begins with the "anticipation of trauma" [10]. This means that a call, for instance, to respond to a potentially life-threatening situation (e.g., a hostage situation) is in itself intense and stressful and that the effect of anticipating trauma intertwines with actual exposure to the potentially traumatic incident. Papazoglou [11] has developed a metaphor that describes the complex and cumulative form of police trauma that he calls the "Police Complex Spiral Trauma" (PCST). His description and developing model is an inclusive and dimensional representation that describes the negative effects of officers' mental and physical health accumulated over the course of their career (often over three decades), to critical incidents that vary in tension, frequency, and unpredictability. In other words, officers' response to trauma such as fatal accidents, crime, child abuse, sex trafficking, homicide, suicide, rape, and more, all have the potential to precipitate a traumatic response. Further, as previously mentioned, the unique nature of trauma in police work is that a police officer's work ranges from carrying out routine tasks and procedures to being required to instantly shift modes to effectively handle a potentially lifethreatening and traumatic situation.

While we need to know more, there have been some research findings suggesting some of the negative effects of trauma on police officers. These findings suggest that there are major negative consequences of unresolved police trauma, including a higher prevalence of alcoholism, serious illnesses related to stress, isolation, family difficulties, lowered concentration [12], sleep disturbances [13], and difficulties concentrating [14]. Further, staying loyal to the police culture while denying the "need" for help, may also lead to behaviors such as eating excessively, gambling, unsafe sex, and attempted or completed suicide [15]. While there is a clear distinction between life stress and trauma and between work-to-family and family-to-work stress, both have been found to predict higher levels of problem drinking and such activities as hazardous drinking [16]. Another important negative effect of trauma that [17-19] found was that the learning process and efficient functioning were both directly and negatively influenced by trauma. This was true for rookies as well as advanced officers.

Another important aspect of police work related to helping behaviors in police officers and trauma was described by Figley [20] and is called "compassion fatigue". He described compassion fatigue as police officers' long-term worry and concern about the possibility of community members being hurt by criminals. This concern reflects police officers usual stance (and self-perception) of being a helper and clearly connects to the expectation that community members will be victims of trauma (and expose police officers to potentially trauma incidents). Tehrani [21] studied compassion fatigue among caring professions. He found that police officers (along with counselors) share the belief that there is no justice in the world. Believing there is no justice also adds to the stress of handling potentially traumatic incidents.

Directly related to experiencing trauma, compassion fatigue Figley [20] can be addressed. Figley [20] described several ways for police officers to deal with compassion fatigue and suggests that education, peer support, self-care, and rest and relaxation are some of the ways officers can use to cope with compassion fatigue. Officers overwhelmingly reported that they prefer talking to a fellow officer rather than a therapist or mental health professional [22]. Specifically, $71 \%$ of Page and Jacobs [22] sample noted that it would better talk to a fellow officer rather than to a therapist, suggesting that peer support rather than receiving mental health services is highly preferred. This reflects the strong stigma associated with seeking help from a mental 
health professional $[6,23]$. Peer to peer programs have been successful in helping to prevent mental health problems and promote well-being [24]. Therefore, sharing and emotional expression among police officers is normal and happens and it helped officers as they officers gave and sought help from their "blue brothers/sisters." Police officers and senior police trainers/educators are in a unique position because they are often first-line responders and therefore, first line helpers.

Another big challenge in resolving trauma for police officers is that the nature of police work results in police officer's developing the view that trauma happens to others, "not me." Victimology is about victims not police officers. In fact, training materials usually emphasize and reinforce the view that police officers go into law enforcement to help keep the peace and ensure order and, hence, they do not view themselves as possible "victims" of loss or trauma. Identifying as being a victim of trauma goes counter to the tenets and principles of the police culture and is not part of the identity of being a police officer.

\section{Training Challenges}

From the aforementioned findings from the literature, it is clear that there is no consensus about the most effective training and education curriculum to produce well-balanced, well-trained, and well-prepared law enforcement officers. In addition, police officers are the primary supports to each other as well as family members after the loss of a colleague and police training has yet to take this into account. Many risks to public safety could result from an unprepared officer or one who is suffering from the effects of unresolved loss and trauma such as increased emotional volatility. This could increase negative perceptions of officers from the communities they serve and resulting decreased community support and trust. These difficulties might be similar to an incident that some senior police trainers witnessed in Germany. Unruly and drunk immigrants being detained by local police officers yelled, "don't touch us you Nazis."

However, it is also very important to recognize another aspect related to the unique character associated with the police culture when considering training about trauma. This is that the usual view that to allow non-police professionals into the culture is like "allowing a Trojan horse into the sacred, insular, and Spartan company of one's brother and sister officers [6]. In contrast to this usual view, the senior police trainers at the Federal German Police University in Muenster, Germany warmly welcomed the first author, Dr. Christiane Manzella, the psychologist and professor from NYU who has been collaborating with the second author, Mr. Konstantinos Papazoglou, Psychology $\mathrm{PhD}$ student at the University of Toronto and Hellenic Police Captain. Authors' assumption of why this happened was that there was a sense that "she's with him, she's okay," reflecting the solidarity of the police culture. That is, the first author, a non-police professional, was welcomed because that professional was brought in to the training by the second author, a senior police trainer/educator.

\section{Instructed and Applied Interventions: Education, Journal Writing, and Mindfulness/Awareness}

Police officers value their work and the police culture so we offered interventions or tools compatible with the police culture. We made the choice of three tools: education, journal writing, and a mindful and awareness exercise we called "be where your feet are." We included these interventions because each can be done independently and does not require the presence of a mental health professional (recognizing the police culture).
As mentioned previously, authors offered trauma education, as experts, to European senior police trainers/educators because there was a request from the European Police College (CEPOL) organizers in step 1 of CEPOL's "Train the Trainers" seminar for more information related to truama. The psychoeducation piece included the second author's lecture related to trauma in step 1 of the seminar held in Athens, Greece, in early March, 2011, titled "Psychology of Police Trainees: Evidence-based and Practice-based interventions in helping Police Trainees within a Culturally Relevant Training Context." In step 2 of the seminar held in the Federal German Police University in Muenster, Germany, second author gave a talk titled "Exploring the Meaning of Loss and Trauma in the Context of Police Training: The Psychology of Survival.” The lectures from the Athens, Greece (step 1) and Munster, Germany (step 2) covered themes related to the police culture, the challenges of police work, and provided the attendees with descriptions of police stress, trauma, and loss and ways officers respond to stress, trauma, and loss (such as the death of fellow officers). These factors were addressed because research findings suggest that stress, trauma, and loss influences the learning process and may interfere with efficient functioning for rookies as well as advanced officers [17-19]. For example, the way a rookie experiences death in the field may be very different from training or field experiences provided in the academy and when a rookie first experiences a loss or trauma, it's important that a tenured officer be at the scene of death [25]. It is crucial that rookies receive guidance on how to handle death and trauma.

We introduced the idea of writing journals because this is an activity that can be done independently and privately. Journal writing has been found to help change memories connected to trauma from being horrific to being a more tolerable "bad" memory and also helps individuals to re-organize the critical incident exposure story through a constructive narrative [26]. In addition, we offered a mindfulness and awareness exercise because this kind of exercise has been found to enhance mental clarity [14] as well as reducing negative emotions and mental ruminations that can be very disruptive to functioning well [27]. We called this exercise, "be where your feet are" in order to make it more practical and an easily understood tool senior police trainers/educators might offer their trainees. Mindfulness and awareness techniques have been found to promote self-awareness along with body awareness. This is similar to the technique of scanning the body while being aware and is a technique we "borrowed" from Eye Movement Desensitization and Reprocessing (EMDR) that is often used with trauma survivors. This technique is part of established treatment protocols for Post-Traumatic Stress Disorder (PTSD) related to trauma [28].

\section{What we Found: What Worked?}

We found that there was a wide range in the knowledge base about trauma and it was clear that the European senior police trainers/ educators valued learning about trauma. Senior police trainers/ educators who had an in-depth knowledge about trauma appreciated having the issues highlighted and discussed and those who had less knowledge about trauma reported that they were eager to learn more. Some of the ways senior trainers reported as ways they responded to loss and trauma and loss included not talking about the trauma. They were also inclined suggest that rookies who experienced trauma talk to someone else.

Because training in the academy focuses on training that helps make procedures automatic to ensure safety, senior trainers expressed having a real desire to link ways of coping (such as mindfulness) with training around specific procedures (such as standard procedures related to 
handling firearms). A big question that came up about the role of police trainers in relation to trauma and loss was considering whether interventions are therapy or teaching. It was clear that senior police trainers/educators made the distinction between their role as educators or as a helper or supportive presence with their trainees. They stressed in their roles as senior police trainers/educators, they are not therapists. We reinforced this view that it is very important to be clear that senior police trainers and teachers at all levels are not psychologists trained to handle psychological difficulties related to trauma. We also reinforced their view that they can be a supportive brother or sister police officer to their trainees. However, the desire to know about and teach efficient and healthy ways to handle trauma and loss was also very clear.

The journals were intended to introduce a way for trainees to explore experiences with loss and trauma. We instructed the senior trainers to write and process a traumatic incident so that they would have a direct experience of journal writing and know how to teach this to their trainees. In their journals written during this training, the descriptions and experiences were very specific. Some described other difficulties, which including increased drinking and numbness along with social isolation. Others described experiencing feelings of shock. Several wrote that remembering and picturing the traumatic event interfered with sleeping. Having a strong desire to fulfill one's duty, no matter what, was clearly conveyed. Those who wrote the journals found them to be cathartic and an intriguing experience.

The participants reported that they very much appreciated the mindfulness and awareness exercise, "be where your feet are," because they felt more relaxed along with having more mental clarity, similar to research findings [14]. As mentioned before, when discussing this exercise, it became clear that there was a desire to link this kind of mindfulness and awareness exercise with actual learning exercises and procedures in the field.

\section{Recommendations for Research and Clinical Practice with Police population}

Based on the aforementioned description of the module authors applied to senior police trainers/educators over the CEPOL's "Train the Trainers" seminar, we make the following points and recommendations to be considered by forensic sciences experts, police managers, police trainers/educators, police researchers, and other professionals and scholars who are actively involved in working with police personnel:

Emphasizing the role of a police trainer and educator as the professional who teaches cadets and other police officers procedures along with healthy ways of handling trauma could be done by using mindfulness and awareness techniques simultaneously with procedures as they are being taught in the field. For example, as previously mentioned, teaching safety with firearms while being aware and mindful. This could begin by visualizing and imagining each step in each procedure while being mindful and aware and then to practice these steps while actually carrying out the field training (potentially increasing concentration and focus).

- Reinforce teaching effective ways of functioning - and mastery of procedures - while encouraging more immediate processing of thoughts and feelings so that there is a lower likelihood of unresolved trauma accumulating over time. One way of processing and coping with loss and trauma we offered was journal writing.
- Because senior police trainers/educators are in the front line working with and providing training to cadets and police, teach the senior police trainers effective listening and communication skills that could potentially improve relations with the community and each other. In addition, effective listening and communication could facilitate fellow officers as they help each other cope with loss and trauma.

- Create bridges between law enforcement professionals and mental health professionals so that the services offered by mental health professionals are "palatable" to police officers and that help build bridges between each profession's subculture and norms.

\section{Conclusion}

Opening a discussion about trauma and loss in an audience of police officers is not an easy task. It is challenging for experts when they receive an invitation to make such a presentation. However, senior police trainers and educators have almost daily contact and communication with police trainees and cadets. This means that they teach and transfer knowledge to active police officers and police cadets who are the next generation of police officers. Thereby, senior police educators and trainers are usually highly respected in the police field by the police personnel. Close communication between mental health professionals and senior police trainers/educators that focuses on the prevention of trauma will hopefully open more discussion about trauma as a topic to be included in the police curricula and police training procedures. This way, senior police trainers and educators, with mental health professionals' collaboration and possible supervision, would be more able to teach and include psychological trauma-related topics and discussion, hence, "break the ice" by offering possible ways and exercises designed to help their trainees more effectively deal with their expected exposure to potentially traumatic incidents. In addition, mental health professionals could use police training procedures as vehicles to enter the police culture. Entering the police culture could enhance their collaboration with police trainers and educators and help police officers become more aware of the impact of psychological trauma in their physical and mental health and, importantly, facilitate instruction from mental health professionals around ways police trainers/educators can effectively help their trainees protect themselves against adversities and potentially traumatic events. This collaborative endeavor also helps us bridge the seemingly unrelated fields that of mental health and that of police, hence, helping police officers maintain overall well-being and functioning while helping to keep peace and order in our communities.

\section{Acknowledgments}

Authors would like to express their gratitude to Dr. Wolfgang Kokoska, Senior Lecturer at the Federal German Police University in Muenster, Germany and Police Lieutenant Kleanthis Papagiannopoulos at the Hellenic Police Academy/Nationa CEPOL Unit for their acceptance and their remarkable support that they provided for the completion of this study over the CEPOL's "Train the Trainers" seminar at the Federal German Police University in Muenster, Germany.

\section{References}

1. Welten B (2010) A brave police force deserves courageous scientists. Afterdinner address at CEPOL police research and science conference 2009 CEPOL European Police Science and Research Bulletin 3: 12-15.

2. Dwyer G, Laufersweiller-Dwyer DL (2004) The need for change. A call for action in community oriented police training. FBI Law Enforcement Bulletin, November, 18-25.

3. American Psychiatric Association (2000) Diagnostic and statistical manual of mental disorders. (4thedn.), Washington, DC. 
Citation: Papazoglou K, Manzella C (2013) Employing Police Training as a Tool of Preventive Intervention of Police Complex Trauma: A Brief Report from a Module Presented at the 2011 European Police College Train the Trainers Seminar. J Forensic Res S11: 004. doi:10.4172/21577145.S11-004

Page 5 of 5

4. Neylan TC, Brunet A, Pole N, Best SR, Metzler TJ, et al. (2005) PTSD symptoms predict waking salivary cortisol levels in police officers. Psychoneuroendocrinology 30: 373-381.

5. Woody RH (2005) The police culture: Research implications for psychological services. Professional Psychology: Research and Practice 36: 525-529.

6. Rudofossi D (2007) Working with Traumatized Police Officer-Patients. A Clinical's Guide to Complex PTSD Syndromes in Public Safety Professionals. Amityville, NY: Baywood Publishing Company.

7. Carlier IV, Lamberts RD, Fouwels AJ, Gersons BP (1996) PTSD in relation to dissociation in traumatized police officers. Am J Psychiatry 153: 1325-1328.

8. Rudofossi D (2009) A Cop Doc's Guide to Public Safety Complex Trauma Syndrome: Using Five Police Personality Styles (Death, Value and Meaning). Amityville, NY: Baywood Publishing Company.

9. Darensbourg MY, Bethel RD (2011) Biomimetic chemistry: Merging the old with the new. Nat Chem 15: 11-13.

10. Van der Kolk BA, McFarlane AC, Weisaeth L (1996) Traumatic Stress: The Effects of Overwhelming Experience on Mind, Body, and Society. New York: The Guilford Press.

11. Papazoglou K (2012) Conceptualizing police complex spiral trauma and its applications in the police field. Traumatology.

12. Hennig-Fast K, Werner NS, Lermer R, Latscha K, Meister F, et al. (2009) After facing traumatic stress: brain activation, cognition and stress coping in policemen. J Psychiatr Res 43: 1146-1155.

13. Papazoglou K (2013) Conceptualizing police complex spiral trauma and its applications in the police field. Traumatology

14. Moore A, Malinowski $P$ (2009) Meditation, mindfulness and cognitive flexibility Conscious Cogn 18: 176-186.

15. Miller L (2005) Police officer suicide: causes, prevention, and practical intervention strategies. Int J Emerg Ment Health 7: 101-114.

16. Pietrzak RH, Schechter CB, Bromet EJ, Katz CL, Reissman DB, et al. (2012) The burden of full and subsyndromal posttraumatic stress disorder among police involved in the World Trade Center rescue and recovery effort. J Psychiatr Res 46: 835-842.
17. Asmundson GJ, Stapleton JA (2008) Associations between dimensions of anxiety sensitivity and PTSD symptom clusters in active-duty police officers. Cogn Behav Ther 37: 66-75.

18. Austin-Ketch TL, Violanti J, Fekedulegn D, Andrew ME, Burchfield CM, et al (2012) Addictions and the Criminal Justice System, What Happens on the Other Side? Post-traumatic Stress Symptoms and Cortisol Measures in a Police Cohort. Journal of Addictions Nursing 23: 22-29.

19. Wang Z, Inslicht SS, Metzler TJ, Henn-Haase C, McCaslin SE, et al. (2010) A prospective study of predictors of depression symptoms in police. Psychiatry Res 175: 211-216.

20. Figley CR (2009) Police Compassion Fatigue (PCF): Theory, Research assessment, treatment, and prevention. In Violanti JM \& Paton, D. (Eds.) Police Trauma: Psychological Aftermath of civilian combat. Springfield, IL: Charles C. Thomas.

21. Tehrani $N$ (2010) Compassion fatigue: experiences in occupational health human resources, counselling and police. Occup Med (Lond) 60: 133-138.

22. Page KS, Jacobs SC (2011) Surviving the shift: Rural police stress and counseling services. Psychological Services 8: 12-22.

23. Wester SR, Arndt D, Sedivy SK, Arndt L (2010) Male police officers and stigma associated with counseling: The role of anticipated risks, anticipated benefits and gender role conflict. Psychology Men \& Masculinity 11: 286-302.

24. Dowling FG, Moynihan G, Genet B, Lewis J (2006) A peer-based assistance program for officers with the New York City Police Department: report of the effects of Sept. 11, 2001. Am J Psychiatry 163: 151-153.

25. Henry VE (2004) Death Work: Police, Trauma, and the Psychology of Survival. New York, NY: Oxford University Press.

26. Richman S (2006) Finding One's Voice: Transforming Trauma into Autobiographical Narrative. Contemporary Psychoanalysis 42: 639-650.

27. Chambers R, Chuen Yee Lo B, Allen NB (2008) The impact of intensive mindfulness training on attentional control, cognitive style, and affect. Cognitive Therapy and Research 32: 303-322.

28. Shapiro F, Maxfield L (2002) Eye Movement Desensitization and Reprocessing (EMDR): information processing in the treatment of trauma. J Clin Psychol 58 933-946.
Citation: Manzella C, Papazoglou K (2013) Employing Police Training as a Tool of Preventive Intervention of Police Complex Trauma: A Brief Report from a Module Presented at the 2011 European Police College Train the Trainers Seminar. J Forensic Res S11: 004. doi:10.4172/2157-7145.S11-004
Submit your next manuscript and get advantages of OMICS Group submissions

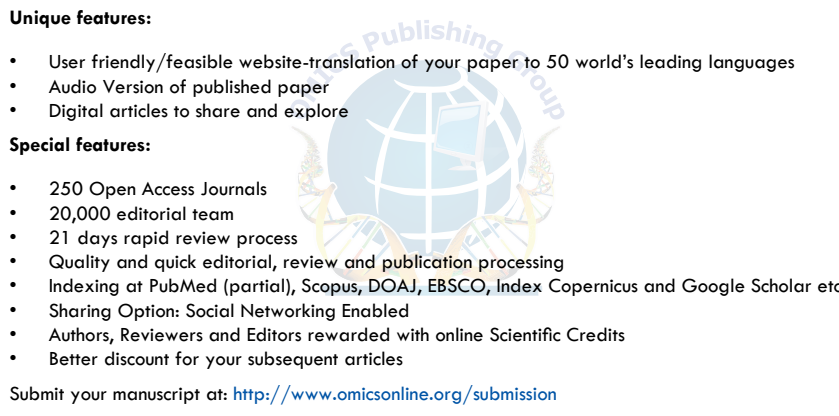

